\title{
How can the risks associated with climate change help shape Lord Howe Island fire management planning
}

\author{
M. J. Beltran \\ Sydney University, NSW Rural Fire Service, \\ University Western Sydney, Australia
}

\begin{abstract}
Lord Howe Island is the most geographically isolated community within the State of New South Wales, lying 600 kilometres east of the Australian mainland in the Pacific Ocean. Apart from the small resident and tourist community the Island boasts an environment that was unseen and therefore untouched by man until the colonisation of NSW but now has numerous threatened and endangered species, some unique to the island.

The Island's climate, with its maritime influence, has to date ensured a very low wildfire risk (and the predominantly natural vegetation communities are susceptible to fire) however, weather records for the Island indicate a small but perceptible temperature increase over the last 50 years and to date there have been isolated periods of unusually low rainfall. Climate anomaly and weather variability may increase fire risk factors for the Island and these are warning signs of a potential increasing exposure to destruction of habitat and threat to residents and visitors.

In an overarching environment where local history indicates that there is a negligible wildfire risk and where the local administration faces considerable competition for its financial and physical resources, the challenge for fire management practitioners is in creating reasonable argument to substantiate potential unseen and previously unknown risk and thereby create an awareness that is adequate to trigger an increased preparedness with community awareness and fiscal and resource planning.

This paper analyses the various State and Commonwealth policies in play for climate change in an emergency management context, the current and potential
\end{abstract}


fire risk management factors, and the challenges facing a small, isolated community in adopting new, different, radical and controversial concepts.

Keywords: risk, climate change, fire management planning, climate anomaly, weather variability, emergency preparedness, community, Lord Howe Island.

\section{Introduction}

Lord Howe Island (the Island) was spared the hand of man until 1788 when the first incursions and interference with its natural order occurred. Whilst the effect of human interference has resulted in the extinction of nine species and the 'endangered listing' of several others, today the Island remains blessed by its natural endowments and the small resident population works hard to keep it clean and green, worthy of its World Heritage status.

Fire is a natural enemy of the Island and its effects, in any other than the most rigorously controlled 'management' uses, will socially, economically and environmentally affect the resident and visitor populations, biodiversity and landscape in some form. At its extreme, fire may have uncompromising and permanently deleterious results.

Not only does the tyranny of distance over ocean add to the cost burden of the fire combat and recovery effort but the ramifications for a small community in terms of social and economic impact can be serious. A recent fire in the Island's power station proved this point. Of course it is hoped that fire will never be the agent of further demise of the Islands unique natural habitats.

Although the effects of climate change still remain unquantifiable in terms of the Island's future, there is a probability that weather events may deviate from the historical averages and that trends of increasing temperatures coupled with possible dry spells may expose the Island environment to increasing wild fire risk.

Lord Howe Island is the most geographically isolated community in NSW. Positioned in the Pacific Ocean approximately 600 kilometres east of Port Macquarie it can only be accessed by sea or air, and both forms of transport are subject to the dictates of weather.

The Island is anomalous in NSW governance; it functions within the NSW system as a distinct and unique bureaucracy/public administration in the form of the Lord Howe Island Board (the Board), which reports to the Minister for Environment, Climate Change and Water. The Island is subject of special legislation, The Lord Howe Island Act 1953, Amended, which gives the Board similar authorities to local government in NSW, and importantly gives it responsibility as the land manager for the Island group (inclusive of the Admiralty Islands, Ball's Pyramid, Blackburn Island, and the adjoining islets). It manages all land, totalling about 1455 hectares, and there is no private land ownership, only leases for which the Board has authority. The small resident community (353 according to the last ABS census) is broken into two groups the first being those related to earlier settlement of the Island, and the second being those others who are engaged in the Islands administration and businesses. 
The Island has the benefits and limitations of human and physical resources expected of a community and bureaucracy of its size, type and isolation.

For the NSW Rural Fire Service (the Service) this difference in governance may explain why, until now, it has simply concentrated on the maintenance of the Island's Rural Fire Brigade, in the forms of training and equipment, but has not progressed with the application of its statutory and other related programs.

There are, though, several compelling reasons to concentrate on the delivery of these government policies in order to strengthen the capacity and resilience of the Island and climate change risk is a prominent reason. There is currently both a challenge and an opportunity for the RFS in complementing the development and delivery of its programs at the Island, with consideration of the possible effects of climate change as enhancements to these programs.

'Fire Management Planning' is a term used to describe a combination of Service statutory and program measures packaged to enhance the process of fire management on the Island. The planning/program matters include the statutory 'Bushfire Risk' [1] and 'Operations Management' Plans (Section 52 of the Rural Fires Act 1997), the Service's 'Standards of Fire Cover' and 'Brigade Classification' programs, a 'Mainland Rapid Response' plan, and forward budget advice. The 'Mainland Response' plan is a unique concept floated especially to address the Island's predicament of isolation and limited resources. The concept of a forward estimate is proposed so as to prepare all parties for financial contribution to equipment or operational requirements that will likely exceed current and historical levels of financing (this affects the Island Board, the Service, the insurance industry and the NSW Government).

Research demonstrates that the fire history (both wildfire and structural fires) of the Island records little fire activity throughout its settled history; the Island was first visited by humans in 1788 and has been settled since then. This relative lack of fire activity (in totality for the Island, and certainly in comparison to the mainland where the use of fire by the traditional owners has helped shape the environment) coupled with the fact that the Island has a sub-tropical characteristic (which naturally lessens fire risk), helps to generate a cultural perception that the Island environment is wildfire resistant, and in some minds, perhaps, even that it has no wildfire threat.

Climate change is recognised as a phenomenon that will progressively threaten and challenge the world's communities and environments. The seriousness of this risk is resonating within the public domain, and climate change treatment is prominent within public policy, as is reflected by the following:

- $\quad$ The NSW Government advises that climate change planning is a State policy [2] (NSW Greenhouse Plan, page 24) "The NSW Government aims to minimise the impacts of climate change through adaptation measures",

The Australian Commonwealth Government [3] pledges that (Australian Greenhouse Office, Climate Change Risk and Vulnerability, Promoting an efficient adaptation response in Australia, 2005, page viii)

- " "...adaptation strategy will aim to increase the resilience of human and natural systems to possible changes in climate conditions...", and, 
The Council of Australian Governments (COAG) [4] promotes positive action (Council of Australian Governments' Plan for Collaborative Action on Climate Change, COAG meeting 10 February 2006, Attachment C, page 1.) "...early action to prepare for this change will minimise costs to our community".

It is generally recognised that climate change will have effect within NSW communities on the fundamental factors that contribute to the occurrence and impact of fires and other emergencies. This is a Service position, anchored in NSW Government (Greenhouse) policy and action. Factoring climate change into the Island's fire management planning is a tool that has two complimentary facets. The first is of course one that adds value to the risk analysis for both the natural and built environment. The second resides in the nature of the changing climate as a 'thought provoker', 'image maker', and 'demanding of action' within the broad community and especially amongst those carrying civic authority. The promotion of climate change risk as an adjunct to fire management planning (in the context of the Island's lack of significant fire history) should greatly assist in driving home the notion that there may be significant potential risks for the Island's communities. Risk management principles provide the tool to look beyond local historically focused prejudices to consider new aspects of 'likelihood' aligned to 'consequence' as the means to measure the impact of events or scenarios.

\section{Fire management frameworks}

The Service provides NSW with statutory and policy programs that create and complement the public safety mantle of measures through preparedness, prevention, recovery and response to emergencies and disasters. These planning measures are generally based upon current risk trends and fire histories, (you will recall that the Island has little fire history and little acknowledgement of current threat trend) but by defining those elements of climate change risk that impact on fire management it becomes possible to promote insights into future risk.

The genesis of the project question comes from experience with the effect of weather variables and short term climate variation. Weather variables in terms of fire danger prediction and wild fire behaviours are those very factors that make one day or period more fire dangerous than those before or after. As fire is dependent on three variables - heat, fuel and oxygen (the 'fire triangle') - the weather elements of temperature, relative humidity and wind strength (and of course fuel load) are all critical factors of wildfire existence and basic behaviour.

Fire fuels within natural environments are generally static within short time periods, but are constantly subject to weather conditions and effects that may at any time add considerably to that fuel load (e.g. very hot and/or dry periods have an effect on eucalypts in that they naturally shed leaves in these conditions, and very strong wind gusts may break branches from trees). For anyone with experience, or perhaps knowledge, of Australian summertime conditions, it comes as no surprise that prevailing weather conditions applied to woodlands and grasslands provides a natural recipe for fire to thrive. Wildfire is accepted as 
being a natural component of the Australian environment, but rainforest is obviously not so readily available to fire (because of the generally prevailing high fuel moisture content, the higher prevailing relative humidity, and because the predominantly closed nature of the forest prevents wind penetration). In fact, whilst much of Australia's flora is fire dependent or fire tolerant, rainforest is fire intolerant.

Although the existence and passage of wildfire in rainforest is uncommon, it has been experienced in NSW and otherwise by the Service. For example, wildfire burning within the forests of the Blue Mountains (The Lawson's Long Alley S44 fire emergency, November 2006, is a good example of wildfire burning unimpeded by rainforest belts) has on occasion, when the drought factors have been high, progressed through rainforest belts which would in other, 'normal' seasons stopped or significantly slowed this wildfire. Another poignant example for the Service was in its assistance to the Malaysian Government in preparatory planning for assistance with wildfires burning in the jungles of Sarawak, Borneo, prior to its Commonwealth Games (The Commonwealth Games were held in Kuala Lumpur in 1998). This example demonstrates that even rainforest of equatorial status burns during pronounced drought. It is important to note at this juncture that fire prediction models have been developed in Australia for eucalypt forest and grasslands, but not for rainforest.

The foregoing supports the notion that if equatorial jungle (as in the Sarawak example) or cool temperate rainforest (as in the Blue Mtns example) can be the subject of wildfire brought about by climatic anomaly, then the mid latitude rainforest of the Island can equally be exposed to fire risk brought about by weather variation/climate change. In judging fire risk and operational constraint, the Island has a plentiful (dormant) fire fuel potential, operationally difficult terrain and the quandary of limited resources and difficulties with logistical back-up/supply (i.e. over distance and via air or sea).

\section{The literature review}

The literature review demonstrates that there is an amount of published knowledge and hypothesis about the general trends and predicted effect of climate change for mainland Australia, some specifically commissioned for NSW. However, beyond agreement within the scientific community that a global rise in sea level will affect the Island (as it will coastlines and tidal reaches globally), there is as yet no common scientific opinion on climate change factors as they may affect the Island.

There are references to climate change risk within both the Board's Biodiversity Management Plan [5] and the NSW Dept of Climate Change (DECC) Lord Howe Island Permanent Park Preserve Draft Plan of Management [6]; both of these plans deliberately (albeit very minimally, but critically) rate climate change risk potentials as noteworthy.

In terms of data and/or information that is available to construct or inform primary research, the following was valuable: 
* The Bureau of Meteorology has measured and collated daily weather readings on the Island since 1886

* The NSW Bushfire Co-ordinating Committee's (BFCC) Policies on 'Bush Fire Risk Planning' and 'Operations Management Planning'

* The spatial information suite held by the Board that contains terrestrial and vegetative data

* Demographic and resource data held by the Board

* Board policy

* Service policy

The Service's Risk Matrix provides a basis by which to measure the potential impacts of the consequence and likelihood of risks, and thus assign a degree of importance of treatment of the risk. The BFCC guidelines cover 'consequence ratings' and 'likelihood ratings', and are of considerable assistance in posing these questions:

1. What is a likely fire frequency? And,

2. If a fire occurs, what are the likely consequences to the natural and/or built environment?

DECC prescribes threat treatment directions which can readily inform the development of the bush fire risk management plan, however, with direct reference to the philosophy of 'natural ecological and land forming processes...being allowed to continue without human interference', there is potentially some conflict with the 'fire management strategies'; this ambiguity demands careful consideration in the development of the fire management Operations Plan. DECC also relates to the 'elimination of trees' on Blackburn Island (part of the Island group), in part to fire, which adds credence to the notion the fire is destructive in at least part of the Island's ecological mix.

The BFCC guideline further calls for information on climate for treatment areas, for which the Aust. Bureau of Meteorology (BoM) data offer weather record statistics for the Island. As bushfire risk is tied to weather variables and available fire (vegetation) fuels, an understanding of the potential for climate change to alter either or both of these factors enables risk assessors to consider potentials beyond historical and contemporaneous limits. DECC further highlights the importance of this factor with a simple reference that climate change may have adverse impact in terms of possible drought, thus inexplicably linking to a key fire danger element.

\section{Climate change and fire risk}

There are already manifestations of a changing climate on the Island. By conducting a comparative analysis of weather data from the BoM's weather station on Lord Howe Island, there is a demonstration of a trend, over time, that the mean maximum and mean minimum monthly average temperatures experienced by the Island have risen. Temperature rise is a benchmark of global warming and an indicator of climate change. This trend is depicted by the following graphs: 

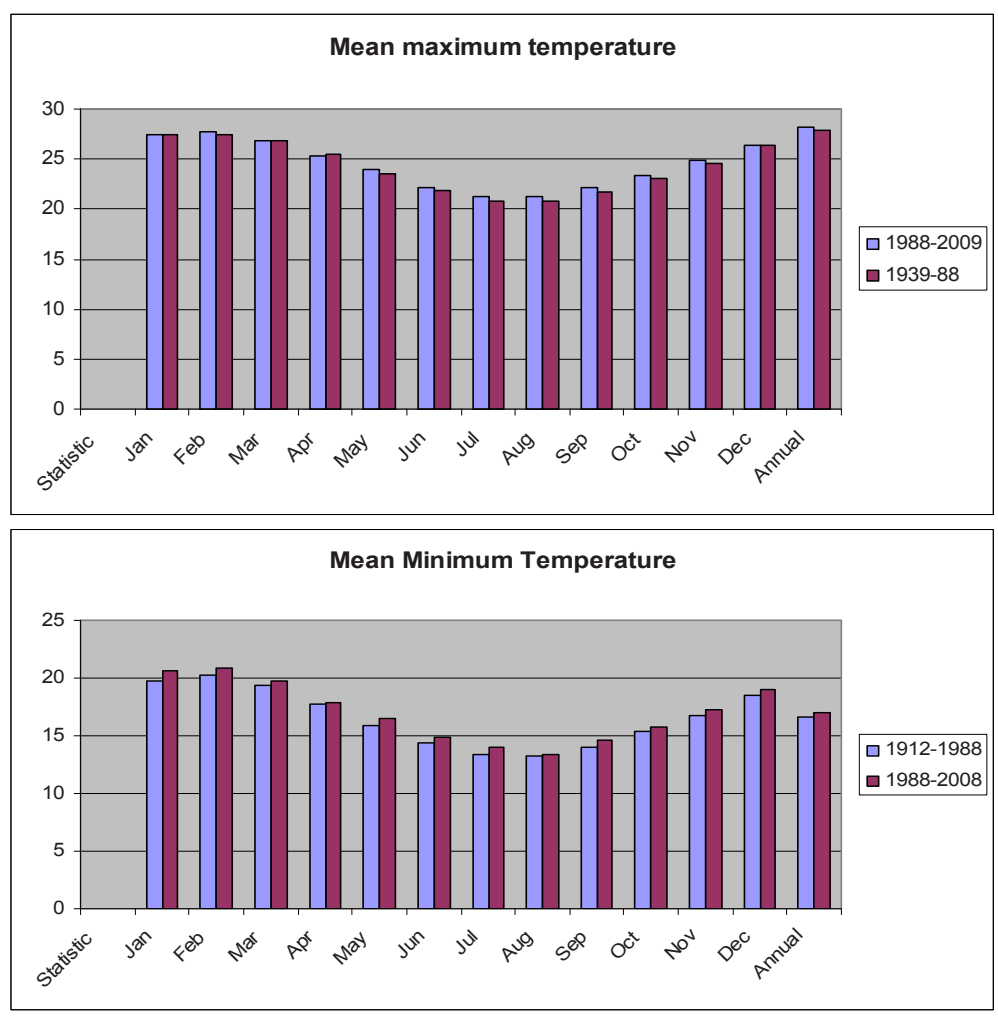

Figure 1: $\quad$ Temperature comparison graphs for Lord Howe Island.

In relation to the comparative time periods, whilst it has been demonstrated the there has been a general trend to rising temperature, the most significant factor was that in regards to the mean maximum temperature readings, that in the 1939-1988 grouping the maximum reached was $29^{\circ} \mathrm{C}$, whereas in the $1988-2008$ grouping the maximum reached was $31.3^{\circ} \mathrm{C}$, a rise in single event terms of $8 \%$. Temperature, you will recall, has a critical significance in wild fire prediction modelling. This questions the potential for future maximum temperature states.

In a report that Professor Ross Bradstock, University of Wollongong, presented to the Service (29/05/09) on climate change and bushfires, he spoke of irregularities in rainfall, i.e. periodic (non regular) drought or dry spells, as being a most significant factor in the development of serious fire dangers in forests. The indication is that the regularity of rainfall will be a victim of the changing climate.

The Board has provided information on seasonal rainfall experiences, inclusive of data that demonstrates the irregularity of rainfall and the irregular incidence of relatively dry summer periods. Over time, the Island has been challenged by these irregular dry spells, albeit that these have to date been of short duration (limited to a month or so). A comparative table demonstrating $20^{+}$ years follows. 
Table 1: Rainfall records for Lord Howe Island, showing the occurrence of months with less that $50 \mathrm{~mm}$ of rainfall for a month, as well as the highest rainfall records (shown shaded) for each of the months within the period.

\begin{tabular}{|c|r|r|r|r|r|r|r|r|r|r|r|r|}
\hline & Jan & Feb & Mar & Apr & May & June & July & Aug & Sept & Oct & Nov & Dec \\
\hline 2010 & & & & & & & & & & & 14 & \\
\hline 2009 & 43 & & & 515 & 48 & & & & & 44 & 15 & 25 \\
\hline 2008 & & & 17 & & & & & & & & & \\
\hline 2007 & 18 & 37 & & & & & & 22.4 & & & & \\
\hline 2006 & & 21 & & & & & & & & & 49 & \\
\hline 2005 & & 30 & & & 322 & & 208 & & & & & \\
\hline 2004 & & & & & & & & & & & 35 & \\
\hline 2003 & & & & & & & & & 45 & & & \\
\hline 2002 & & & & & & & & & & & 29 & \\
\hline 2001 & 35 & & 290 & & & & & & & & 286 & \\
\hline 2000 & & 5 & 38 & & & & & & & & & \\
\hline 1999 & & & & & & & & & & & & \\
\hline 1998 & & 524 & & & & & & & & 230 & & \\
\hline 1997 & 41 & 34 & & 43 & & & & & & 49 & 27 & 38 \\
\hline 1996 & 480 & & & & & 562 & & & & & & 40 \\
\hline 1995 & & 39 & & & & & & 41 & & & & \\
\hline 1994 & & 26 & & & & & & & & & & \\
\hline 1993 & & & & 34 & & & & & 166 & & & \\
\hline 1992 & & & & & & & & & & & & \\
\hline 1991 & & & & & & & & & & 27 & & 245 \\
\hline 1990 & & & & & & & & 286 & & & & 33 \\
\hline 1989 & & 30 & & & & & & & & & & \\
\hline
\end{tabular}

This monthly rainfall record (1989-2010) demonstrates an erratic pattern of rainfall for the Island; note however that some months have recorded very low rainfall, as low as 5 millimetres (February 2000). Note that during this period there have some relatively dry spells of consecutive months.

As previously referenced, forest fuel moisture content and grassland curing, both the subject of (the lack of) rainfall, have critical significance in wildfire prediction modelling. Given that the BoM statistics also confirm that the Island is regularly the subject of winds of strength, we already have a confluence of fire weather features (temperature, dryness and wind). This demonstrates possibilities for elevated wildfire risk given the known climate change trends of temperature rise, coupled with the possibilities of the Island suffering drought (DECC Lord Howe Island Biodiversity management Plan, 'Potential threats', page 32) [5] and with the ever present possibility of strong, steady wind.

One of the weather factors that make any environment less prone to the risk of serious fire is high relative humidity - it essentially works as a cooling agent by adding moisture to fire fuels. BoM records demonstrate that relative humidity on the Island is predominantly above $50 \%$; thus adding to the general belief that there is little prevailing fire danger there. The weather readings are however taken near sea level, and, apart from the work that DECC is currently undertaking at and near the summit of Mt Gower, there is still the question of relative humidity differing due to elevation or Island environments. 
This was tested in a simple field experiment which measured temperature and humidity across landscape and within forest environments, conducted on the Island on 10th May 2009, using a Kestrel portable weather meter along the Goat House Cave track, as follows:

Table 2: $\quad$ Humidity over elevation and terrain study, Lord Howe Island.

\begin{tabular}{|l|c|c|c|}
\hline Place/elevation & Temp $^{\mathbf{}} \mathbf{C}$ & Humidity \% & Barometer \\
\hline Soldier's Ck, $17 \mathrm{~m}$ & 20.2 & 54.6 & 1014.3 \\
\hline $76 \mathrm{~m}$ & 17.6 & 55.7 & 1006.8 \\
\hline 127 (saddle) & 17.3 & 49.7 & 1006.6 \\
\hline 146 & 18.1 & 51.9 & 998.6 \\
\hline 182 & 17.8 & 45.9 & 994.4 \\
\hline 212 & 19.2 & 49.2 & 990.8 \\
\hline 229 (Creek crossing) & 18.4 & 48.7 & 989.0 \\
\hline 266 & 18.1 & 49.8 & 984.7 \\
\hline 322 & 18.6 & 53.3 & 978.3 \\
\hline 367 & 19.2 & 53.6 & 972.7 \\
\hline 407 & 18.4 & 49.6 & 968.2 \\
\hline 442 & 22.5 & 47.4 & 964.1 \\
\hline 452 (Goat House & 19.8 & 44.9 & 963.2 \\
Cave) & & & \\
\hline 235 (Creek crossing) & 19.7 & 47.1 & 988.1 \\
\hline
\end{tabular}

As previously stated, this was a very simple test, but it did demonstrate variables of temperature and humidity across the landscape. The differences in humidity readings in the Goat House Cave track environment were substantial.

Another pertinent question relates to the effect of ENSO [7] (the El Niño Southern Oscillation) on the Island; does the Island parallel the mainland in the manifestation of droughts (El Niño) and floods (La Niña). A comparative analysis of ENSO readings and Island rainfalls for two four year blocks 19972000 and 2005-2008 revealed no discernable correlation between ENSO and the Island's precipitation patterns.

These two four year blocks were chosen because they contain some pronounced positive and negative sequences. One notable outcome from this study is that, as yet, there is nothing to suggest why the Island has had the serious dry spells that it has occasionally suffered, and thereby denying forecasters a prediction tool by which to prepare for, and mitigate against, fire weather periods.

\section{Programs and policies}

The Service has begun the facilitation of a Fire Management Planning suite for the Island that necessitates the engagement of the Service and the Board (and other players dictated by role as prescribed by the NSW Bush Fire Co-ordinating 
Committee) to develop robust and co-operative arrangements to mitigate against and minimise unwanted fire.

The Bush Fire Risk plan, in particular, will have an impact for the protection of the Island's people and its built and natural environments by the identification of special and specific risk areas. The Operations Management plan will ensure the co-ordination of the emergency responders and land management authority into a co-operative response community. The Service's other programs of standard of fire cover and brigade classification will ensure that appropriate resourcing levels are agreed and that the Island's fire responders are suitably equipped for their role.

The requirement to ensure that this plan links to and complements the Board's plan of management of the Permanent Park Preserve and the Biodiversity Management Plan is obvious. Although anthropogenic climate change is listed as a Key Threatening Process (The Biodiversity Management Plan, pages 20-31, lists 15 Key Threatening Processes) for the Island's biodiversity, further consideration to listing wildfire to this grouping may be warranted.

\section{Conclusion}

The primary conclusion is that the Island is potentially the subject of weather anomaly/climate variability that could present the onset of unprecedented and largely unexpected fire dangers to the built and natural environments. Given the issues of the Island's geographic isolation, the limitations of its resources, the nature of the Island's unique natural environment and the criticality of early fire detection and rapid suppression, it is important that fire planning measures are targeted and robust and that climate change potentials are captured in the risk analysis. The Service's work with the Risk Management and Operations Management Plans are key first steps to this goal.

The very factors that affect this small, isolated and precious environment are undoubtedly at play at many other such rare locations around Australia and the world and it is important that any emergency planning systems that use historical trend factors of weather and incident occurrence as trusted, perhaps sole, benchmarks for program development bear in mind the radical short duration variables that climate variation can produce.

Co-operation between governments, administrations and authorities is crucial to meeting the challenges of emergency management, especially in a climate change context, with the potentials for development of monitoring systems, fiscal and administrative perspicacity inclusive of knowledge sharing and joint research arrangements, and the refinement of rapid emergency response systems inclusive of pre-deployment in sensitive situations.

\section{References}

[1] The Bush Fire Coordinating Committee, NSW, 2008, Policy 1/2008, Bush Fire Risk Management, Sydney 
[2] Dept. of Environment and Climate Change (NSW), 2008, NSW Climate Action Plan, Dept. of Environment and Climate Change (NSW), Sydney

[3] Dept. of The Environment and Heritage, Australian Greenhouse Office, Climate Change Risk and Vulnerability, Promoting an efficient adaptation response in Australia, 2005, page viii http://bss.sfsu.edu/naff/PA740 /strategy\%20docs/risk-vulnerability-summary.pdf

[4] The Coalition of Australian Governments (COAG), 2006, National Climate Change Adaptation Framework, (part of Plan of Collaborative Action on Climate Change), COAG, http://www.coag.gov.au/coag_meeting_outcomes /2007-04-13/docs/national_climate_change_adaption_framework.pdf

[5] Dept. of Environment and Climate Change (NSW), 2007, Lord Howe Island Biodiversity Management Plan, Dept. of Environment and Climate Change (NSW), Sydney

[6] Dept. of Environment and Climate Change (NSW), NSW National Parks and Wildlife Service, 2007, Lord Howe Island Permanent Park Preserve Draft Plan of Management, Dept. of Environment and Climate Change (NSW), Sydney

[7] Australian Greenhouse Office, Dept of Environment and Heritage, 2005, What is the El Niño-Southern Oscillation (ENSO)?, (part of the series 'Hot Topics in Climate Change Science'), Canberra

\section{Other applicable reading}

Australian Greenhouse Office, Dept of Environment and Heritage, 2005, Could Global Warming Affect the Thermohaline Circulation?, (part of the series 'Hot Topics in Climate Change Science'), Canberra

Australian Greenhouse Office, Dept of Environment and Heritage, 2006, Climate Change Impacts and Risk Assessment: A Guide for Business and Government, Australian Government, Canberra

Baines, P(Dr), 1998, Australia's Climate Cerberus, The puzzle of three oceans, ECOS 97, Oct-Dec 1998, CSIRO Publishing, Canberra

Bostock, H, Opdyke, B, Gagan, M, Kiss, A, Fifield, L., 2006, Glacial/interglacial changes in the East Australian Current, Climate Dynamics, Vol26, No.6, May 2006, SpringerLink, Heidelberg

CSIRO, 2009, Indian Ocean temperature Link to Bushfires, Greenhouse 2009, ref 09/49, CSIRO Publishing, Canberra

CSIRO, 1998, Reading the Eddies, p.19, Ecos, Vol.1989, No. 94, Jan-Mar 1998, CSIRO Publishing, Canberra

Dept of Climate Change, Australian Govt., 2008, Climate Change Science, Frequently Asked Questions, Canberra 
Hennessey, K, Lucas. C, Nicholls. N, Bathols, R, Suppiah, R, Ricketts. J., 2005, Climate Change Impacts on Fire Weather in South-east Australia, (CSIRO Marine and Atmospheric Research, Bushfire CRC, and Aust, Bureau of Meteorology), CSIRO Marine and Atmospheric Research, Aspendale, Victoria

Lin, M, Dexing, W, Xue'en, C, Jungclaus, J., 2006, Analyses of the predicted changes of the global oceans under the increased greenhouse gas scenarios, Chinese Science Bulletin, 2006, Vol 51, China

McGregor, S., 2008, What is ENSO and how predictable is it?, Risk Frontiers Quarterly Newsletter, October 2008, Macquarie University, Sydney

NSW Rural Fire Service, 2004, Risk Matrix: Service Delivery Model, eSDM vers. 2.0, Standard Operating Procedures, P54, NSW Rural Fire Service, Sydney

NSW Rural Fire Service, 2006, Service Delivery Model, Standard of Fire Cover, NSW Rural Fire Service, Sydney

NSW Rural Fire Service, 2007, Brigade Classification, Standard Operating Procedure 1.1.15-1, NSW Rural Fire Service, Sydney

Pitman, A., 2008, Modelling future climates: where are we and what's next?, Risk Frontiers Quarterly Newsletter, October 2008, Macquarie University, Sydney

Preston, B, Brooke, C, Measham, T, Gorddard, R, 2008, Igniting change in local government: lessons learned from a bushfire vulnerability assessment, Springer Science and Business Media, Dordrecht, Netherlands

Richardson, A., 2008, Climate Change and Oceans, ECOS, Dec-Jan 2008, CSIRO Publishing, Canberra

Rintoul, S, Meyers, G, Church, J, Godfrey, S, Moore, M, Stanton, B., 1996, Ocean Processes, Climate and Sea Level, Greenhouse, page 127 of Coping with Climate Change, CSIRO Publishing, Canberra

Sharp, A., 2008 Assessing risk from meteorological phenomena using limited and biased databases, The Australian Journal of Emergency Management, Vol. 23 No. 4, Nov 2008, Canberra

Sullivan, K., 2008 Policy implications of future increases in extreme weather events due to climate change, The Australian Journal of Emergency Management, Vol. 23 No. 4, Nov 2008, Canberra

Williams. S., Jacobs. K., Newton. P., Blakely. E.J., 2009, Natural disaster preparation: a guide for state housing authorities, Australian Housing and Urban Research Institute (AHURI) Positioning Paper No. 13, Feb 2009, Melbourne 